\title{
Strengths or bias in social LCA?
}

\author{
Alessandra Zamagni • Oscar Amerighi • Patrizia Buttol
}

Received: 29 March 2011 / Accepted: 26 May 2011 / Published online: 5 June 2011

(C) Springer-Verlag 2011

Social life cycle assessment (S-LCA) emerged in the last years as a methodological approach aimed at evaluating social and socioeconomic aspects of products and their potential positive and negative impacts along their life cycle. According to the Guidelines for social life cycle assessment of products (Benoît and Mazijn 2009), developed within the UNEPS/SETAC Life Cycle Initiative, social impacts are those that may affect stakeholders along the life cycle of a product and may be linked to company behaviour, socioeconomic processes and impacts on social capital. This definition includes two strengths of S-LCA that together distinguish it from other social assessment methods: (1) the focus on the product and (2) the broad definition of social impacts, which encompasses both the company behaviour and the socioeconomic perspective.

From a company perspective, one of the main added values of S-LCA is the possibility to spend the results of the evaluation on the market. This could be achieved, for example by means of a social label, in a way similar to what is done for the carbon footprint.

Based on the powerful potential of S-LCA, the authors would like to point out that the two strengths of the

\footnotetext{
A. Zamagni $(\bowtie) \cdot$ P. Buttol

LCA \& Ecodesign Laboratory,

Italian National Agency for New Technologies,

Energy and Sustainable Economic Development (ENEA), via Martiri di Monte Sole 4,

40129 Bologna, Italy

e-mail: alessandra.zamagni@enea.it

O. Amerighi

Research \& Study Unit,

Italian National Agency for New Technologies,

Energy and Sustainable Economic Development (ENEA), Lungotevere Thaon di Revel 76,

00196 Rome, Italy
}

methodology might also represent a source of bias and risks, if not dealt with properly and responsibly. We would like to briefly work this concept out, giving hints for further reflection.

Starting from the focus on the product, the functional unit (FU) comes into the discussion. This concept is at the core of LCA, but it shows critical aspects when applied in the context of social evaluations.

Let us consider the case of a company producing product $x$ and one supplier of theirs, producing a component of $x$ as well as other products/components. The supplier might make use of child labour for manufacturing several products but not the component of $x$, for example because different production lines are involved (this issue has already been discussed by Jørgensen et al. 2009). If we apply the S-LCA to the assessment of product $x$ by focusing on the product system itself, this deplorable behaviour could not be caught, because the supplier would carry responsibility only for that part of production included in the product system $x$. This would be a step back with respect to the corporate social responsibility, which pushes companies to mature a high sense of responsibility for and within the company as a whole.

However, the S-LCA framework is strongly based on a company perspective, i.e. a perspective that links the socioeconomic impacts to the behaviour of a company. The importance of connecting the social impacts mainly to the conduct of a company and not to the function delivered by a given product is emphasised in the literature by several authors (see e.g. Dreyer et al. 2006). This is further confirmed by the many boycott campaigns initiated by consumer groups or other stakeholders when the social performance of a company was deemed to be inadequate or poor under different aspects. We may cite, for instance, the Nike boycott launched in the 1990s against the inhuman 
treatment of workers and the exploitation of child labour in Southeast Asia plants (Wikipedia 2011a); the sustained criticisms of the Coca-Cola Company since the early 2000s concerning questionable labour practices, engagement in monopolistic business operations and violations of intellectual property rights (Wikipedia 2011b); the Nokia boycott urged by German unions in 2008 in response to the decision to close production sites in Germany and to move production to lower-cost regions in Eastern Europe (Reuters 2008).

So, in our opinion, there seems to be a contradiction in requiring a FU approach and a company perspective within the same framework. As the goal is the improvement of social aspects related to a product system, is it appropriate to apply the FU concept in the same way as we do in environmental LCAhence to relate the social performance to the unit processes directly involved? Can the concept of company behaviour, i.e. considering the responsibility of the companies involved in the life cycle of the product and of their suppliers, coexist with the FU concept? And if yes, how should it be managed?

Another aspect concerning the focus on the product should be also discussed: social impacts are intrinsically related to the specific geographical and cultural context where they unfold. In fact, the same product, produced in different parts of the world, is likely to cause different social impacts in terms not only of different values for a specific indicator but also of different relevant indicators. Consider, for instance, the case of the Italian carmaker Fiat Group. Several car models are assembled in different plants of the group worldwide, like the 500 in Poland and Mexico; the Grande Punto in the Italian plant of Melfi, in Brazil and in India; the Doblò in Brazil and Turkey (Fiat Group Automobiles 2009). Being the car model the same, we may anticipate that the assessment of the social impacts will require the analysis of different aspects, depending on the production site. However, if we intend to assess the specific product (e.g. to introduce a social label), we need to refer the impacts to the FU and to calculate an average value, i.e. an average of the different socioeconomic conditions in the geographical locations considered. But what is the meaning of averaging social impacts that occur several thousand kilometres distant? And in addition, how can a change of location be assessed? Take the example of the Fiat Group that announced its intention to shut down the production of the Lancia Ypsilon model in its Italian assembly site of Termini Imerese by the end of 2011 and to move production in the Polish site of Tichy. The social consequences of such a decision are quite evident but can hardly be seized and quantified if we refer to the FU concept or even to a company perspective.

The last point allows us to introduce the discussion on the second strength of S-LCA, the broad definition of social impacts given in the guidelines. This definition embeds the literature on Social Impact Assessment and Technology Assessment by including also socioeconomic processes and impacts on social capital. However, this seems to be in partial contradiction with the framework developed for the impact assessment, hence the sub-categories and indicators proposed, as the focus on the company behaviour is the dominant one (see for example Hauschild et al. 2008; Dreyer et al. 2010).

Social impacts in S-LCA are mainly related to the way a specific company manages social aspects of concern along the whole supply chain. Even for the stakeholder "Society" three out of five subcategories analyse social impacts in terms of degree of engagement of the company in social issues (contribution of an organisation to sustainable development for Public commitment to sustainability issues; its role in armed conflicts for Prevention and mitigation of armed conflicts; measures put in place by an organisation to prevent corruption for Corruption). A perspective that considers how the development of a product would affect the social structure in which it will be embedded seems to be lacking. This point of view is considered of fundamental importance and evidence is given in the scientific literature. Some authors (Assefa and Frostell 2007; Labuschagne and Brent 2006) agree on defining social impacts as those related to individual well-being and to interactions among individuals. Vanclay (2003) speaks of changes occurred in the way people satisfy their needs as citizens embedded in society.

A shared perspective of these definitions is that a social impact arises whenever a product interacts with the surrounding system and gives rise to positive or negative consequences. Thus, whenever a change occurs in the system. Consequently, the product cannot be analysed in isolation, neglecting the consequences that might arise from its introduction into the market. Paraphrasing the LCA terminology, the adoption of a societal perspective implies that a ceteris paribus assumption does not hold: interrelations exist that need to be evaluated.

This is particularly clear when significant changes occur, as it is the case, for example, for a new/innovative technology. In fact, its development and introduction into the market generate multiple dynamics that might have important effects on the whole society, contributing for example to the creation of employment, to economic development, to knowledge generation and evolution.

The reader might think that reasoning in terms of social consequences, resembles the consequential approach, as developed in LCA. Thus, the distinction between attributional and consequential modelling could apply in S-LCA. The concept of consequential S-LCA has been introduced by Jørgensen et al. (2010) but with a different meaning, i.e. an assessment that includes the non-implemented life cycle situation in addition to the implemented one. The reasoning behind is that social impacts occur also when a process is not carried out.

However, we think that the distinction between attributional and consequential is neither relevant nor pertinent in 
S-LCA. The consideration of social consequences should be the main goal of any social assessment. This implies evaluating the extent to which the main ingredients of a society are affected (McMillan and Chavis 1986):

- people (socioeconomics and demographics, health status and risk profiles);

- connectors (shared values, interests, motivating forces);

- power relationships (communication patterns, formal and informal lines of authority and influence, stakeholder relationships, resource flows).

This logic, introduced also in S-LCA, would make the assessment more complete but would also probably require the introduction of new stakeholder categories, sub-categories and indicators, in whose definition the support of other methods can play an important role.

In this short letter, we pointed out that two of the main characteristics of S-LCA, i.e. the FU approach and the definition of social impacts, could be a source of bias if not dealt with properly. Only the development of case studies on a wide range of products/systems will help in understanding to what extent a broader, not FU-based, perspective in the social assessment is necessary, giving also further elements to finetune the methodology. We encourage practitioners to open a debate on it, considering also the role of S-LCA in the context of a life cycle sustainability assessment (Kloepffer 2008).

\section{References}

Assefa G, Frostell B (2007) Social sustainability and social acceptance in technology assessment: a case study of energy technologies. Technol Soc 29:63-78
Benoît C, Mazijn B (eds) (2009) Guidelines for social life cycle assessment of products. Social and socio-economic LCA Guidelines complementing environmental LCA and Life Cycle Costing, contributing to the full assessment of goods and services within the context of sustainable development. UNEP/SETAC Life Cycle Initiative, Paris, France

Dreyer LC, Hauschild MZ, Schierbeck J (2006) A framework for social life cycle impact assessment. Int J Life Cycle Assess 11 (2):88-97

Dreyer LC, Hauschild MZ, Schierbeck J (2010) Characterisation of social impacts in LCA: part 1: development of indicators for labour rights. Int J Life Cycle Assess 15(3):247-259

Fiat Group Automobiles (2009) http://www.fiatgroup.com/it-it/media centre/group/Documents/MEDIAKIT_2009_ITA/FGA.pdf Accessed March 18th 2011

Hauschild MZ, Dreyer LC, Jørgensen A (2008) Assessing social impacts in a life cycle perspective-lessons learned. CIRPAnnals -Manuf Technol 57:21-24

Jørgensen A, Hauschild MZ, Jørgensen MS, Wangel A (2009) Relevance and feasibility of social life cycle assessment from a company perspective. Int J Life Cycle Assess 14(3):204-214

Jørgensen A, Finkbeiner M, Jørgensen MS, Hauschild MZ (2010) Defining the baseline in social life cycle assessment. Int J Life Cycle Assess 15(4):376-384

Kloepffer W (2008) Life cycle sustainability assessment of products. Int J Life Cycle Assess 13(2):89-95

Labuschagne C, Brent AC (2006) Social indicators for sustainable project and technology life cycle management in the process industry. Int J Life Cycle Assess 11(1):3-15

McMillan DW, Chavis DM (1986) Sense of community: a definition and theory. J Community Psychol 14:6

Reuters (2008) German unions urge Nokia boycott over plant closure. January 17,2008

Vanclay F (2003) Conceptual and methodological advances in social impact assessment. In: Becker HA, Vanclay F (eds) The international handbook of social impact assessment - conceptual and methodological advances. Edward Elgar, Boston

Wikipedia (2011a) http://en.wikipedia.org/wiki/Nike,_Inc Accessed March 18th, 2011

Wikipedia (2011b) http://en.wikipedia.org/wiki/Criticism_of_CocaCola Accessed March 18th, 2011 